American Journal of Applied Sciences 6 (1): 194-199, 2009

ISSN 1546-9239

(C) 2009 Science Publications

\title{
Biological Control of Rice Blast (Magnaporthe oryzae) by use of Streptomyces sindeneusis isolate 263 in Greenhouse
}

\author{
${ }^{1}$ M. Ebrahimi Zarandi, ${ }^{2}$ G.H. Shahidi Bonjar, ${ }^{3}$ F. Padasht Dehkaei, \\ ${ }^{4}$ S.A. Ayatollahi Moosavi, ${ }^{5}$ P. Rashid Farokhi and ${ }^{2}$ S. Aghighi \\ ${ }^{1,2}$ Department of Plant Pathology, \\ College of Agriculture, Shahid Bahonar University of Kerman \\ ${ }^{3}$ Rice Research Institute, Rasht \\ ${ }^{4}$ Department of Medical Parasitology and Mycology, \\ College of Medicine, Medical University of Kerman, Kerman \\ ${ }^{5}$ Department of Agronomy and Plant Breeding, \\ College of Agriculture, Shahid Bahonar University of Kerman, Iran
}

\begin{abstract}
Soil Actinomycetes particularly Streptomyces spp. have antagonistic activity against wide range of plant pathogens. In the recent decades they have attracted high interests as biocontrol agents. In search for finding such principles, in vitro suppression of Magnaporthe oryzae the causal agent of rice blast disease was studied by use of Streptomyces sindeneusis isolate 263 in greenhouse. Spray of rice seedling-leaves with of mixed spore suspension of the pathogen and S. sindeneusis isolate 263 resulted in strong inhibition of the pathogen and suppression of leaf symptoms. Propagation of the antagonist crude sap was performed in aqueous cultures and bioactivity was monitored in shaked cultures. Ongoing goals of this research include isolation, characterization and identification of the active metabolites and future goals include identification of active genes for use in development of recombinant DNAs in transgenic rice varieties bearing elevated resistance to infections by M. oryzae.
\end{abstract}

Key words: Magnaporthe oryzae, Pyricularia oryzae, Streptomyces, Actinomycetes, Biocontrol

\section{INTRODUCTION}

Streptomyces are one of the most attractive sources of biologically active substances such as vitamins, alkaloids, plant growth factors, enzymes and enzyme inhibitors $^{[1-3]}$. Soil Streptomycetes are of the major contributors to the biological buffering of soils and have roles in decomposition of organic matter conductive to crop production ${ }^{[4,5]}$. Studies even show that use of Streptomycetes enhances growth of the crop plants $^{[6]}$. The search for new principles in biocontrol of plant pathogens different from the classical used fungicides, is of world wide concern ${ }^{[7-9]}$. Biological control of plant diseases is slow, gives few quick profits, but can be long lasting, inexpensive and harmless to life. Rice blast, caused by Magnaporthe oryzae (anamorph Pyricularia oryzae Cav.), is considered the most important disease of rice because of its world-wide distribution and the resulting severe yield $\operatorname{loss}^{[10]}$. At the present research 100 isolates of
Actinomycetes were isolated from agricultural soils of Kerman of Iran and screened against M. oryzae in vitro. The objective of the present study was also to isolate Streptomyces isolates having antagonistic properties with the aim that they can serve as gene donors in developing resistant transgenic plants and use as soil amendments as biofertilizer or biofungicide in biological control of the tested pathogen. From all tested isolates of Actinomycetes, 10 Streptomyces isolates showed high in vitro anti rice-blast activity.

\section{MATERIALS AND METHODS}

Culture media and preparation of pathogen: Pure culture of Magnaporthe oryzae was obtained from $\mathrm{Mr}$. Padasht, Iran Rice Research Institute (IRRI), Rasht. The pathogen was maintained on potato dextrose agar (PDA, Difco-39 g PDA L ${ }^{-1}$ of distilled $\mathrm{H}_{2} \mathrm{O}, \mathrm{pH}$ 7.2). Casein glycerol agar (CGA) was prepared from basic

Corresponding Author: M. Ebrahimi Zarandi, Department of Plant Pathology, College of Agriculture, Shahid Bahonar University of Kerman, Kerman 
ingredients as described by Kuster and Williams ${ }^{[11]}$ and used as Actinomycetes culture.

Soil sampling and isolation of streptomycetes: Soil samples were collected from grassland, orchards and vegetable fields in different localities of Kerman provinces, Iran. Several samples randomly were selected from the mentioned localities using an openend soil borer (20 cm in depth, $2.5 \mathrm{~cm}$ in diameter) as described by Lee and Hwang ${ }^{[12]}$. Soil samples were taken from a depth of 10-20 cm below the soil surface. The soil of the top region $(10 \mathrm{~cm}$ from the surface) was excluded. Samples were air-dried at room temperature for 7-10 days and then passed through a $0.8 \mathrm{~mm}$ mesh sieve and were preserved in polyethylene bags at room temperature before use. Samples $(10 \mathrm{~g})$ of air-dried soil were mixed with sterile distilled water $(100 \mathrm{~mL})$. The mixtures were shaken vigorously for $1 \mathrm{~h}$ and then allowed to settle for $1 \mathrm{~h}$. Portions $(1 \mathrm{~mL})$ of soil suspensions (diluted $10^{-1}$ ) were transferred to $9 \mathrm{~mL}$ of sterile distilled water and subsequently diluted to $10^{-2}$, $10^{-3}, 10^{-4}, 10^{-5}$ and $10^{-6}$. Inocula consisted of adding aliquots of $10^{-3}-10^{-6}$ soil dilutions to autoclaved CGA $\left(1,25 \mathrm{~mL}^{-1} \mathrm{CGA}\right)$ at $50^{\circ} \mathrm{C}$ before pouring the plates and solidification. Three replicates were considered for each dilution. Plates were incubated at $30^{\circ} \mathrm{C}$ for up to 20 days. From day 7 on, Streptomyces colonies were isolated on CGA, incubated at $28^{\circ} \mathrm{C}$ for one week and stored refrigerated as pure cultures before use. For screening studies 100 pure Streptomyces isolates were collected.

Antifungal bioassays: To evaluate the antifungal activity of isolated Streptomyces against the pathogen, bioassays were performed in agar disk method as used by Shahidi Bonjar ${ }^{[2]}$. Antifungal activity around the Streptomyces agar disks was evaluated as follows and the ratings used were modified from those of Lee and Hwang $^{[12]}$ and El-Tarabily et al. ${ }^{[13]}$ : (1) no inhibition $=$ mycelial growth not different from control $(-) ;(2)$ weak inhibition $=$ partial inhibition of mycelial growth, measured as a diameter of 5-9 mm (+); (3) moderate inhibition $=$ almost complete inhibition of mycelial growth, measured as a diameter of 10-19 mm $(++)$; 4) strong inhibition $=$ complete inhibition, in which most mycelia did not grow, measured as a diameter of $>20 \mathrm{~mm}(+++)$. Controls included plain agar disks.

Monitoring activity in shaked culture: Streptomyces isolate 263 was grown in submerged culture of CG medium on rotary shakers under $130 \mathrm{rpm}$ at $29^{\circ} \mathrm{C}$. To monitor the activity, small aliquots of culture media were taken every $24 \mathrm{~h}$ for 108 days and the activity was evaluated by well diffusion-method ${ }^{[14,15]}$.

Classification of the active antagonists: From ten active Streptomyces isolates one showed high antagonistic activity and their colonies were characterized morphologically and physiologically to the genus level following the direction mentioned in the methods manual of international cooperative project for description and deposition of cultures of Streptomyces $(\mathrm{ISP})^{[16]}$. Identification procedures of the active isolates were done by Saadoun et al., Dept. of biological sciences, University of Science and Technology, Irbid, Jordan as described by Saadoun and Gharaibeh ${ }^{[17]}$.

Determination of minimum inhibitory concentrations (MIC): To measure the MIC values, two-fold serial dilutions of 50, 25, 12.5, 6.25, 3.125, 1.562 and $0.781 \mathrm{mg} \mathrm{ml}^{-1}$ of the crude extract were prepared in DM solvent and assayed by well diffusionmethod as described by Shahidi Bonjar ${ }^{[18]}$. The MIC was defined as the lowest concentration able to inhibit any visible fungal growth. All data represent average of three replicated experiments.

Solubility studies of active crude in organic solvents: To evaluate the relative polarity of the active principle (s) present in the crude, $2 \mathrm{~mL}$ of each of $\mathrm{H}_{2} \mathrm{O}$, methanol and chloroform were added to $20 \mathrm{mg}$ pulverized-crude samples separately and vortexed for $20 \mathrm{~min}$. Each sample was then centrifuged at $3000 \mathrm{rpm}$ for $15 \mathrm{~min}$ using a bench low speed centrifuge. Supernatants and pellets were separated, at $50^{\circ} \mathrm{C}$ and assayed at concentration of $20 \mathrm{mg} \mathrm{mL} L^{-1}$ by Agar diffusion$\operatorname{method}^{[19]}$.

Effect of chloroform on active principle (s): To confirm the result of chloroform sensitivity, $15-20 \mathrm{~mL}$ of chloroform was added to $300 \mathrm{mg}$ pulverized-crude and were maintained on rotary shakers under $130 \mathrm{rpm}$ at $29^{\circ} \mathrm{C}$ for $24 \mathrm{~h}$. Then vortexed and divided to three small tubes, supernatants and pellets were separated and dried as above. Equal volumes of chloroform were added to each tube, vortexed and centrifuged and dried under reduced air, the quantitative experiment was conducted as above two times. Then tubes were placed in a desiccator for $24 \mathrm{~h}$. All samples were tested by well diffusion method.

Determination of shelf life or stability of active crude: To measure the stability of the active crude in soluble state, $5 \mathrm{mg} \mathrm{mL}^{-1}$ samples were prepared in distilled water and placed in small vials. These samples 
were kept at room temperature and tested using Agar diffusion-method for anti $M$. oryzae activity at 14 days intervals as long as the activity persisted.

Determination of thermal inactivation point (TIP): Small aliquots $\left(10 \mathrm{mg} \mathrm{mL}^{-1}\right)$ of soluble crude were exposed to each of $30,40,50,60,70,80$ and $90^{\circ} \mathrm{C}$ for $10 \mathrm{~min}$ and cooled on ice afterwards to monitor the effect of temperature on bioactivity. For temperatures over than $90^{\circ} \mathrm{C}$ heat oil is used. Bioactivity of treated samples was evaluated using well diffusion method. Control included incubation of an untreated sample at $29^{\circ} \mathrm{C}^{[20]}$.

Detection of fungicidal and/or fungistatic activity: Small blocks of inhibition zones $\left(1 \mathrm{~mm}^{3}\right)$ of $S$. sindeneusis against $M$. oryzae was transferred to fresh PDA plates and incubated for 7 days at $26-28^{\circ} \mathrm{C}$. During incubation, growth or lack of growth of the fungus was investigated both visually and microscopically. Rejuvenation of growth was indicative of fungistatic and lack of growth represented fungicidal properties of the antagonist.

Greenhouse studies: Seeds of commercial rice Oryza sativa L. (cv. Kazemi) grown under greenhouse conditions in plastic pots containing sterilized sand and humus of decayed leaves $(3: 1 \mathrm{w} / \mathrm{w})$. Seeds were planted 3-4 cm below soil surface per pot. In three leaves-stage, they were separated in four groups with ten pots in each and treated in following groups: (a) pathogen alone, (b) S. sindeneusis isolate 263, (c) pathogen plus S. sindeneusis isolate 263 and (d) control (untreated). Spore suspension of the pathogen was prepared by adding 2-3 mL sterile distilled water to Petri dishes of well grown lawn culture of the pathogen and collecting the liquid in small beakers. For inoculation, a conidial suspension of $M$. oryzae $\left(4 \times 10^{5}\right.$ conidia $\left.\mathrm{mL}^{-1}\right)$ with Triton X-100 (250 ppm) was sprayed on the treated rice plants. At the same time selected mixtures of culture filtrates from $S$. sindeneusis isolate 263 plus pathogen and isolate 263 alone were sprayed on rice plants separately in b and c treatments. Controls included use of tap water instead of spore suspension. Percentage of diseased leaf area of fifty plants per treatment was determined according to the method developed by International Rice Research Institute (IRRI). The rice seedlings were desoiled, washed and incubated for $48 \mathrm{~h}$ at $60^{\circ} \mathrm{C}$ to measure the dry weights. The experiment was repeated twice and means recorded.

\section{RESULTS}

Antifungal bioassays: From tested Actinomycete isolates, ten isolates were active in dual culture methods. Figure 1 shows two antagonists and the suppressive reaction of $M$. oryzae. Figure 2 shows bioassay results of $S$. sindeneusis isolate 263 against $M$. oryzae measured in agar disk-method. In both methods, S. sindeneusis isolate 263 show antifungal inhibitory effects on the pathogen.

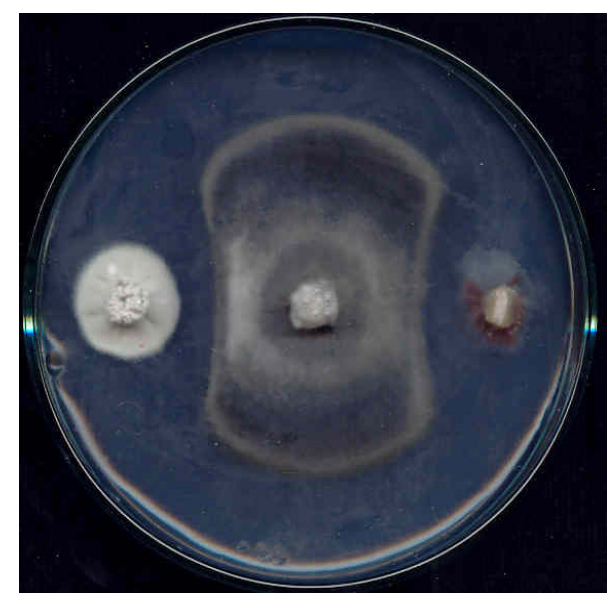

Fig. 1: Suppressive reaction of two Streptomyces isolates on Magnaporthe oryzae. Left: Streptomyces isolate 339 and right: Streptomyces isolate 328. Center disk is Magnaporthe oryzae agar disk which its growth towards the antagonists is inhibited clearly

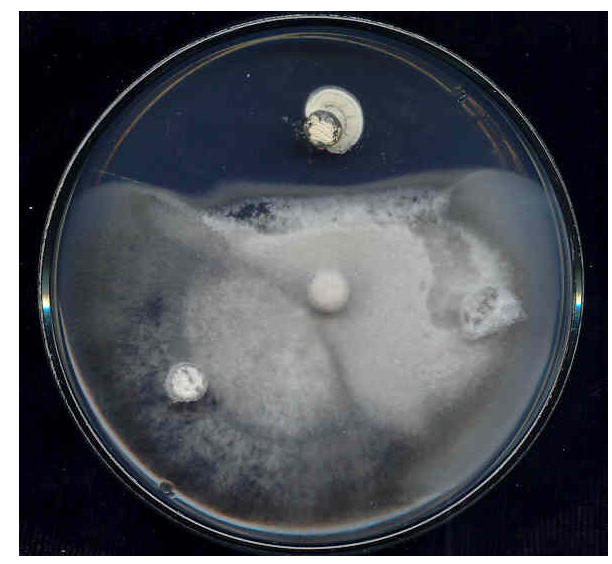

Fig. 2: Bioassay results of Streptomyces isolates against Magnaporthe oryzae. Clockwise from top: Streptomyces sindeneusis isolate 263, blank agar disk (control), the Streptomyces isolate 202. Center disk is Magnaporthe oryzae agar disk 
Am. J. Applied Sci., 6 (1): 194-199, 2009

Table 1: Morphological and physiological characterization of Streptomyces sindeneusis isolate 263

\begin{tabular}{lllllllllllll}
\hline $\begin{array}{l}\text { Arial mycelium } \\
\text { color }\end{array}$ & $\begin{array}{l}\text { Melanoid } \\
\text { pigments }\end{array}$ & $\begin{array}{l}\text { Reverse } \\
\text { color }\end{array}$ & $\begin{array}{l}\text { Soluble } \\
\text { pigments }\end{array}$ & $\begin{array}{l}\text { Spore } \\
\text { chain }\end{array}$ & $\begin{array}{l}\text { Spore } \\
\text { surface }\end{array}$ & $\begin{array}{l}\text { L- } \\
\text { Arabinose D- }\end{array}$ & $\begin{array}{l}\text { Xylose } \\
\text { I- }\end{array}$ & $\begin{array}{l}\text { Inistol } \\
\text { D- }\end{array}$ & D- & Rannitol Fructose \\
Rhamnose & Sucrose Raffinose \\
\hline Yellow/White & 0 & 0 & 0 & F & Sm & + & + & - & + & + & - & - \\
\hline
\end{tabular}

F: Flexuous; Sm: Smooth; 1: Positive; 0: Negative;-: No utilization; +: Utilization

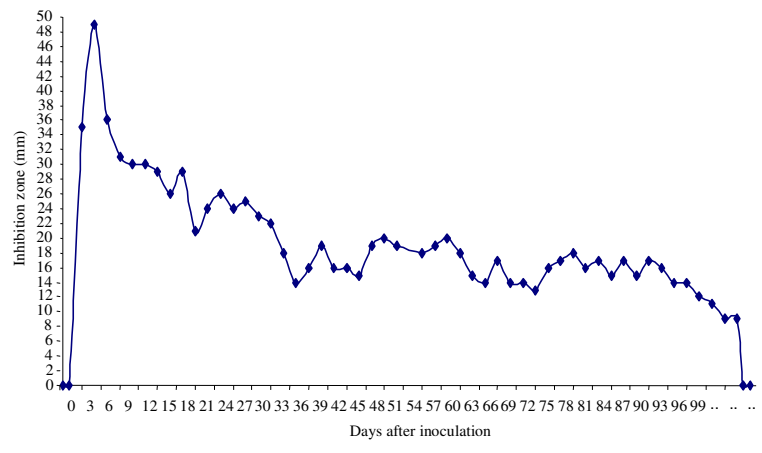

Fig. 3: In vitro bioassay results of Streptomyces sindeneusis isolate 263 against Magnaporthe oryzae in rotary cultures indicative of production time versus inhibition zones

Monitoring activity and growth curve: Activity reached maximum after 5 days in rotary cultures. In shaked cultures, this interval was used to harvest cultures to prepare crude extract for use in further investigations. Activity versus post seeding time in rotary cultures is presented in Fig. 3.

Taxonomy of streptomyces isolate 263: Isolate 263 was identified as Streptomyces sindeneusis isolate 263 which is a new record from Iran. Table 1 shows the complete identification of this isolate based on morphological and biochemical characterization. Figure 4 shows scanning electron micrograph of spore chains of $S$. sindeneusis isolate 263.

Determination of MIC: In well diffusion-method, MIC of the crude was determined as $3.125 \mathrm{mg} \mathrm{mL}^{-1}$ against $M$. oryzae.

Solubility active crude in organic solvents: Solubility results are indicated in Table 2. As the results show, apparently there is more than one active principle involved since activity is traceable both in polar and nonpolar solvents of $\mathrm{H}_{2} \mathrm{O}$, methanol and chloroform.

Shelf life or stability of active crude: Stability of the active crude in distilled water at room temperature (12$30^{\circ} \mathrm{C}$ ) was about six months, assayed by using Agar diffusion-method against $M$. oryzae.
Table 2: Bioassay results of solubility tests of the antifungal principle(s) of Streptomyces sindeneusis isolate 263 against Magnaporthe oryzae in fractions of different solvents indicated by well diffusion-method at $20 \mathrm{mg} \mathrm{mL}^{-1}$ of dry crude

\begin{tabular}{llll}
\hline Solvent & Fraction* & Activity & $\begin{array}{l}\text { Inhibition } \\
\text { zone }(\mathrm{mm})\end{array}$ \\
\hline $\mathrm{H}_{2} \mathrm{O}$ & SP & ++ & 1820 \\
Methanol & SP & ++ & 2112 \\
hloroform & SP & ++ & 1522 \\
\hline *S: Supernatant, P: Pellet & &
\end{tabular}

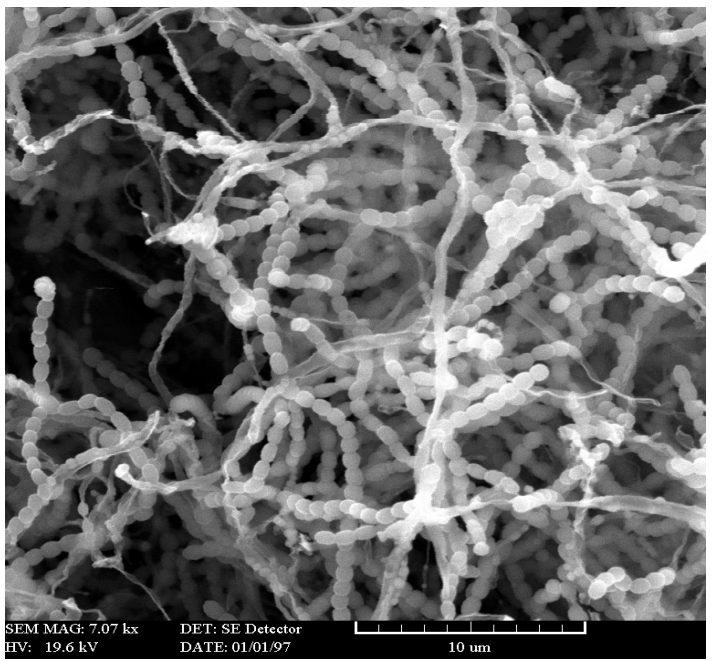

Fig. 4: Scanning electron micrograph of spore chains of Streptomyces sindeneusis isolate 263

Determination of TIP: Bioactivity of active isolate diminished to zero at $170^{\circ} \mathrm{C}$.

Fungicidal and/or fungistatic activity: Transfer of blocks from inhibition zones to fresh PDA plates revealed afterward growth of the pathogen which was indicative of fungistatic activity of $S$. sindeneusis.

In vivo greenhouse studies: The results of biological control of Streptomyces sindeneusis isolate 263 against M. oryzae the causal agent of rice blast are indicated in Fig. 5. Treatment of plants with pathogen only resulted typical blast symptoms and percent of diseased leaf area evaluated $8 \%$ and in treatment of plants with pathogen plus Streptomyces evaluated $0.5 \%$ according to the method developed by IRRI. That is indicative of significant reduction in the number of lesions in pots 


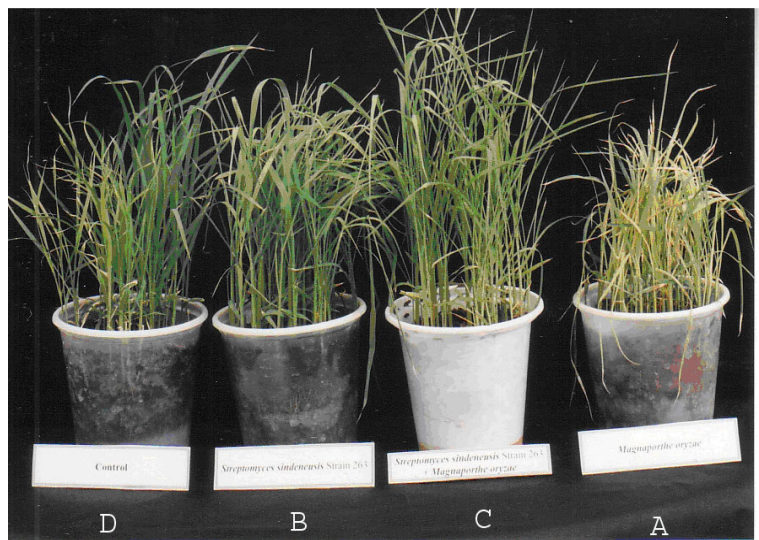

Fig. 5: In vivo greenhouse results in rice plants indicative blast disease (A) in plants inoculated with the pathogen alone and (B) plants inoculated with the Streptomyces sindeneusis isolate 263 alone, (C) plants inoculated with both pathogen and the antagonist, $S$. sindeneusis isolate 263 and (D) untreated control plants
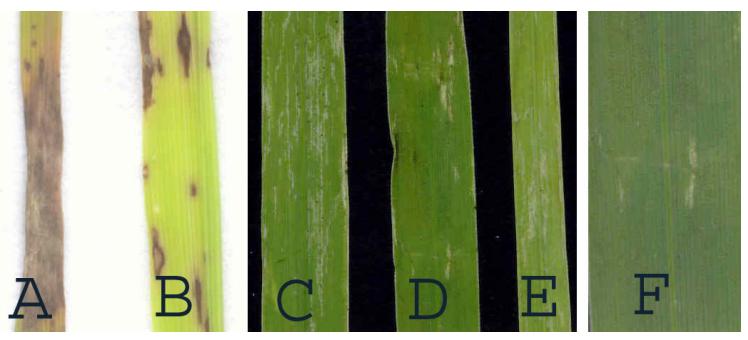

Fig. 6: Comparative result of Biological activity of Streptomyces sindeneusis isolate 263 against Magnaporthe oryzae on rice seedlings. (A, B): indicate leaf symptoms resulted from infections by $M$. oryzae and (C-F): show the effect of mixed spore sprays of leaves with both S. sindeneusis isolate 263 and the pathogen which indicates strong inhibition in blast development

which received the antagonist. Treatment of rice plants with antagonist in B and C groups had no significant effect on dry weight of rice plants. Figure 6 indicates comparative result of biological activity of $S$. sindeneusis isolate 263 against $M$. oryzae on rice seedlings. A and B indicate leaf symptoms resulted from infections by $M$. oryzae and $\mathrm{C}-\mathrm{F}$ show the effect of mixed spore sprays of leaves with both S. sindeneusis isolate 263 and the pathogen which indicates high degree of inhibition in blast development.

\section{DISCUSSION}

In sustainable agriculture natural biofungicides are safe and pro environment. Since most of synthetic fungicides do harm the ecosystem to some extent, their usage should be banned and switched to safer strategies as biological control techniques. Our findings represent the presence of potential antifungal metabolite (s) in $S$. sindeneusis isolate 263 against $M$. oryzae. Antifungal activity of the isolate found in this study highlights its importance as a candidate for further investigation in biological control of the world-wide destructive rice blast disease. The genes encoding many antifungal characteristics are currently being used by agribusiness to create genetically modified plants that have increased fungal resistance in the field. We believe that the results of these findings can form the avenue for production of resistant transgenic-plants with recombinant DNA having antifungal genes cloned from biologically active Streptomyces isolates which would lead to environmentally safer measures in plant-pest management.

\section{ACKNOWLEDGMENTS}

This research is dedicated to Mr. A. Afzalipour and Mrs. Fakhereh Saba the founders of Universities in Kerman. This paper is part of M. Ebrahimi Zarandi dissertation fulfilled for degree of Master of Science in Dept. of Plant Pathology, College of Agriculture, Kerman University of Shahid Bahonar, Kerman, Iran.

\section{REFERENCES}

1. Omura, S., 1986. Philosophy of new drug discovery. Microbiol. Rev., 50: 259-279.

2. Shahidi Bonjar, G.H., 2003. In vitro monitoring of antibacterial properties of soil Streptomyces. Research project report. Department of Plant Protection, College of Agriculture, Bahonar University of Kerman, Iran.

3. Shahidi Bonjar, G.H., M.H. Fooladi, M.J. Mahdavi and A. Shahghasi, 2004. Broadspectrim, a Novel Antibacterial from Streptomyces sp. Biotechnology, 3: 126-130.

4. Gottlieb, D., 1973. General Consideration and Implications of the Actinomycetes. In: Actinomycetales: Characteristics and Practical Importance, Sykes, G. and F.A. Skinner (Eds.). Academic Press, London, pp: 1-5. 
5. Keiser, T., M.J. Bibb, M.J. Buttner, K.F. Chater and D.A. Hopwood, 2000. General introduction to actinomycete biology. In: 'Practical Streptomyces Genetics'. The John Innes Foundation, England, pp: $1-21$.

6. Brown, M.E., 1974. Seed and root bacterization. Annu. Rev. Phytopathol., 12: 181-197.

7. Fruh, T., P. Chemla, J. Ehrler and S. Farooq, 1996. Natural products as pesticides: Two examples of stereoselective synthesis. Pestic. Sci., 46: 37-47.

8. Knight, S.C., V.M. Anthony, A.M. Brady, A.J. Greenland, S.P. Heaney, D.C. Murray, K.A. Powell, M.A. Schulz, C.A. Sinks, P.A. Worthington and D. Youle, 1997. Rationale and perspectives on the development of fungicides. Annu. Rev. Phytopathol., 35: 349-372.

9. McSpadden Gardener, B.B. and D.R. Fravel, 2002. Biological control of plant pathogens: Research, commercializationand application in the USA. http://www.apsnet.org/online/feature/biocontrol/to p.html.

10. Te Beest, D.O., Guerber, C. and M. Ditmore, 2007. Rice blast. The Plant Health Instructor. http://www.apsnet.org/Education/LessonsPlantPath /RiceBlast/default.htm.

11. Kuster, E. and S.T. Williams, 1964. Selection of media for isolation of Streptomyces. Nature, 202: 928-929.

12. Lee, J.Y. and B.K. Hwang, 2002. Diversity of antifungal Actinomycetes in various vegetative soils of Korea. Can. J. Microbial., 48: 407-417.
13. El-Tarabily, K.A., M.H. soliman, A.H. Nassar, H.A. A1-hassani, K. Sivasithamparam, F. McKenna and G.E.St.J. Hardy, 2000. Biological control of Sclerotinia minor using a chitinolytic bacterium and Actinomycetes. Plant Pathol., 49: 573-583.

14. Dhingra, O.D. and J.B. Sinclair, 1995. 'Basic plant pathology methods'. CRC Press, USA, pp: 287-296, 390-391.

15. Acar, J.F. and F.W. Goldstein, 1996. Disk Susceptibility Test. In: Antibiotics in Laboratory Medicine. 4th Edn. William and Wilkins Co, Baltimore, pp: 1-51.

16. Shirling, E.B. and D. Gottlieb, 1966. Methods for characterization of Streptomyces species. Int. J. Syst. Bacteriol., 16: 313-340.

17. Saadoun, I. and R. Gharaibeh, 2002. The Streptomycetes flora of Jordan and its potential as a source of antibiotics active against antibioticresistant Gram-negative bacteria. World J. Microbiol. Biotechnol., 18: 465-470.

18. Shahidi Bonjar, G.H., 2004. New approaches in screening for antibacterials in plants. Asian J. Plant Sci., 3: 55-60.

19. Shahidi Bonjar, G.H., 2004. Screening for antibacterial properties of some Iranian plants against two strains of Escherichia coli. Asian J. Plant Sci., 3: 310-314.

20. Nawani, N.N. and B.P. Kapadnis, 2004. Production dynamics and characterization of the chitinolytic system of the Streptomyces sp. NK1057, a well equipped chitin degrader. World J. Microbiol. Biotechnol., 20: 47-494. 